\title{
The molecular basis for the prothrombotic state in sickle cell disease
}

\author{
Arun S. Shet, ${ }^{1}$ Maria A. Lizarralde-Iragorri ${ }^{1}$ and Rakhi P. Naik ${ }^{2}$ \\ ${ }^{1}$ Laboratory of Sickle Thrombosis and Vascular Biology, National Heart, Lung, and Blood \\ Institute, NIH, Bethesda and ${ }^{2}$ Division of Hematology, Department of Medicine, Johns \\ Hopkins University, Baltimore, MD, USA
}

Haematologica 2020

Volume 105(10):2368-2379

\section{Correspondence:}

ARUN S. SHET

arun.shet@nih.gov

Received: April 6, 2020.

Accepted: July 22, 2020.

Pre-published: August 13, 2020.

doi:10.3324/haematol.2019.239350

(C)2020 NIH (National Institutes of Health)

\section{ABSTRACT}

T he genetic and molecular basis of sickle cell disease (SCD) has long been characterized but the pathophysiological basis has not been entirely defined. How a red cell hemolytic disorder initiates inflammation, endothelial dysfunction, coagulation activation, and eventually leads to vascular thrombosis, is yet to be elucidated. Recent evidence has demonstrated a high frequency of unprovoked/recurrent venous thromboembolism (VTE) in SCD, with an increased risk of mortality among patients with a history of VTE. Here, we provide an in-depth review of the molecular basis for the prothrombotic state in SCD, specifically highlighting emerging evidence for activation of overlapping inflammation and coagulation pathways that predispose to venous thromboembolism. We share perspectives in managing venous thrombosis in SCD, highlighting innovative therapies with the potential to influence the clinical course of disease and reduce thrombotic risk, while maintaining an acceptable safety profile.

\section{Introduction}

Renewed interest in sickle cell disease (SCD) as a significant global health problem by academia, industry and policy makers is leading the resurgence of efforts to treat or cure patients with this disease. Drug development has recently led to US Food and Drug Administration (FDA) approval of three new agents (L-glutamine, crizanlizumab, voxelotor) adding much needed diversity to the hitherto lone disease-modifying therapy, hydroxyurea (HU). ${ }^{1}$ Moreover, advanced phase clinical trials of molecules targeting diverse disease mechanisms, if efficacious, could ameliorate the protean manifestations of SCD. In addition, curing SCD either through stem cell transplantation or gene therapy has become a reality for a small number of patients. ${ }^{2}$ Given the October 2019 joint National Institutes of Health (NIH)-Bill and Melinda Gates Foundation funding declaration, inclusion of patients from high disease burden resource-scarce settings in such trials of novel curative therapies seems plausible. ${ }^{3}$ Prospects appear particularly promising for SCD patients in resource-scarce settings worldwide, where the need is greatest.

Despite these advances, many patients with SCD continue to experience severe complications, and understanding the pathophysiology of "downstream" events remains important for the development of therapies to target specific complications. One of these phenomena is the sickle prothrombotic state that is largely believed to be responsible for both arterial and venous thrombosis in SCD. In its most devastating form, thrombosis occurs in arteries leading to overt stroke and silent cerebral infarction in SCD patients as early as childhood. ${ }^{4,5}$ In adulthood, SCD patients develop deep venous thrombosis (DVT) and pulmonary embolism $(\mathrm{PE})$, collectively termed venous thromboembolism (VTE). ${ }^{6.8}$ Thrombotic vasculopathy in SCD is accompanied by significant organ dysfunction, morbidity from diminished quality of life, and mortality. ${ }^{6,7}$ Yet, how the complex pathobiology initiated by sickle RBC-mediated endothelial inflammation/dysfunction and coagulation activation leads to vessel injury, leakage, and vascular thrombosis remains to be clarified. At the mechanistic level, there is a scientific gap in our understanding of coagulation-mediated pathologies of SCD, a fact noted in the National Heart, Lung, and Blood Institute (NHLBI) evidence-based guidelines, ${ }^{9}$ which makes this an active area of research. Therefore, gaining insight into the patho- 
physiological basis for the prothrombotic state in patients with SCD and how one might attenuate thrombotic risk is of the utmost importance. Studies of vascular pathobiology using in vitro and animal models of SCD have identified both insightful and discrepant findings, when compared with human SCD, as noted in the accompanying review in this issue of the Journal by Conran and De Paula. ${ }^{10}$ Here we examine the molecular basis for the prothrombotic state and establish the scientific rationale to target dysregulated coagulation pathways in patients with SCD. For a more comprehensive overview of arterial thrombosis and/or SCD management, the reader is referred to recent publications in the literature. ${ }^{1,11-13}$

\section{Sickle cell disease: an acquired hypercoagulable state}

The underlying mechanism(s) for the prothrombotic tendency in SCD has been the subject of speculation for many decades. ${ }^{14,15}$ Several clinical observations suggest that the presence of sickle hemoglobin $(\mathrm{HbS})$ is either directly or indirectly associated with the development of thrombotic complications in SCD. The early age of onset of arterial complications such as stroke and silent cerebral infarction in children with hemoglobin SS disease, in particular, is a clear example of the thrombotic potential associated with hemoglobin S. Furthermore, in adults, a wide range of sickling hemoglobinopathies have been associated with the development of VTE, from hemoglobin SS to compound heterozygous states to sickle cell trait (SCT).

Numerous epidemiological studies of VTE in SCD have verified an increased risk of this complication (Table 1). A retrospective analysis of the Cooperative Study of SCD demonstrated a $11.3 \%$ cumulative incidence of VTE by the age of $40,{ }^{16}$ and a similarly high incidence was found in a large California discharge database. ${ }^{7}$ These estimates are particularly striking when compared to population studies of patients with thrombophilia, as the incidence rates of VTE observed in SCD are similar to those found in families with high-risk thrombophilia such as protein $\mathrm{C}$ and S deficiency. ${ }^{16}$ In addition, after controlling for confounding factors such as hospitalization, studies have found that VTE rates are high even among SCD with a lower number of hospitalizations, ${ }^{7}$ and that VTE prevalence in pregnant women with SCD increases approximately 5 -fold compared to non-SCD pregnant women. ${ }^{17,18}$ Furthermore, the recurrence rate of VTE in SCD has also been noted to be exceedingly high ( $>35 \%$ at 5 years), another indication of the persistent thrombogenic potential in SCD.

Further confirmation of the relationship between the presence of $\mathrm{HbS}$ and a prothrombotic state are observations noted in healthy individuals with SCT. In two large population-based studies, VTE risk in individuals with SCT was almost 2-fold higher than ethnic-matched counterparts, despite the absence of either clinical sickling symptoms or HbS percentages encountered in patients with SCD (Table 1). 19,20 As with the known pathophysiology of SCD complications, the presence of $\mathrm{HbS}$ alone is unlikely to be the sole contributor to thrombotic risk. Additional mechanisms, described further below, are likely to contribute to the acquired prothrombotic state in SCD.

\section{Clinical and genetic risk factors for the prothrombotic state}

Clinical and biological factors provide insight into why a genetic disorder primarily involving red cells sets off a cascade of events leading to an acquired prothrombotic state. Risk factors for VTE in SCD include increased disease severity (as measured by averaging $\geq 3$ hospital admissions a year for VOC), exposure to erythropoiesis stimulating agents or blood transfusion, insertion of central venous catheters (CVC), surgical splenectomy, and hospitalization. ${ }^{21-24}$ As mentioned above, not only are SCD patients at a high risk for developing early onset VTE, but their risk for VTE recurrence after an index VTE has been noted to be high. Clinical risk factors for VTE recurrence include averaging $>3$ hospital admissions a year, lower extremity DVT as the index event, and a prior history of pneumonia/acute chest syndrome (ACS), ${ }^{8,23}$ Incomplete adherence to anticoagulation is also likely to contribute to higher recurrence rates, though this has not been formally evaluated. In a single center retrospective study, use of direct oral anticoagulants (DOAC) was associated with lower recurrence rate..$^{23}$

Genotype may also modify thrombotic risk in SCD. Certainly, children with $\mathrm{HbSS} / S \beta^{0}$ are at highest risk for arterial thrombosis such as stroke. ${ }^{5,23}$ In terms of VTE, the influence of genotype has not been fully elucidated, with some studies demonstrating an increased risk of VTE among sickle variant syndromes and others showing the highest risk among $\mathrm{HbSS} / \mathrm{S} \beta^{0} .^{6,16}$ The influence of co-inheritance of either $\alpha$-thalassemia or gene modifiers regulating human fetal hemoglobin expression ${ }^{25-27}$ or both, has not been studied for VTE but may attenuate stroke risk. ${ }^{5}$

The influence of heritable thrombophilia mutations on VTE risk in SCD remains to be completely determined. Genetic variants, factor V Leiden and prothrombin FII G20210A in particular explain up to $50 \%$ of unprovoked VTE among Caucasians. ${ }^{28}$ Notably, VTE risk is 5-fold higher in individuals reporting African descent compared with those reporting Asian descent, whereas white individuals have only an intermediate-level risk. ${ }^{29}$ However, factor V Leiden and prothrombin FII G20210A have low allele frequencies among individuals reporting African descent and are not associated with venous thrombosis in SCD. ${ }^{30,31}$ Thus, other heritable or acquired thrombophilia-associated mutations could explain thrombotic risk in SCD. One recent study identified two known thrombomodulin gene variants (THBD rs2567617 and rs1998081) that were associated with arterial and venous thrombosis in SCD patients. ${ }^{23}$ A recent genome-wide association study conducted among African Americans in the general population identified three novel intronic gene variations (LEMD3, LY86, LOC100130298) associated with higher odds of developing VTE. ${ }^{32}$ LEMD3 encodes for a nuclear membrane protein that interacts with transforming growth factor (TGF)- $\beta$ to downregulate the activation of TGF- $\beta$ target genes ${ }^{33,34}$ and $L Y 86$ encodes for MD-1, which regulates expression of a cell surface protein homologous to toll-like receptor (TLR) $4 .{ }^{35,36}$ Given the involvement of the innate immune system in both VTE ${ }^{37}$ and the vascular pathobiology of $S C D, 10$ genetic dysregulation of these pathways in SCD patients could influence thrombophilia. Acquired mutations also influence thrombotic risk; $J A K 2^{\mathrm{V} 617 \mathrm{~F}}$ the most frequent age-induced clonal hematopoietic mutation is associated with increased 
venous thrombotic events. ${ }^{38}$ Future studies may clarify the role of these heritable or acquired mutations.

\section{Thrombo-inflammatory processes in sickle cell disease that alter hemostatic balance}

A triad of thrombosis risk factors first described by Virchow that includes increased blood coagulability, altered blood flow (stasis) and endothelial dysfunction, are all evident in SCD. ${ }^{39}$ The endothelium, a critical regulator of thrombo-inflammatory processes maintains vascular health by exerting anti-coagulant, anti-inflammatory, and anti-platelet actions. The sickle proinflammatory state leads to endothelial dysfunction, thereby shifting the hemostatic balance towards a prothrombotic state (Figure 1). Accumulated evidence suggests that SCD is a thrombo-inflammatory disorder as reflected by alterations in components of coagulation and inflammatory pathways. ${ }^{40.43}$ This is most clearly demonstrated in the acute exaggerated thrombo-inflammatory response that accompanies ischemia-reperfusion (IR) injury in SCD patients. ${ }^{44}$ Endothelial inflammation leads to surface expression of adhesion molecules (P-selectin and E-selectin) and release of prothrombotic granule contents (von Willebrand factor and FVIII), both effects enhancing leukocyte/platelet adhesion (Figure 2). Repeated VOC episodes amongst other pathophysiology leads to hemolysis and subsequent release of cell-free heme/hemoglobin. By activating converging inflammatory pathways, such as TLR signaling, ${ }^{45}$ NETosis/neutrophil extracellular trap (NET) formation ${ }^{46}$ and priming the inflammasome, ${ }^{47}$ cell-free heme amplifies inflammation (Figures 1 and 2). ${ }^{48}$ Inflammation, shear stress and hypoxia, which are common phenomena in VOC, under experimental conditions can induce abnormal endothelial TF gene and protein expression. ${ }^{49.51}$ SCD

Table 1. Epidemiological studies of venous thromboembolism (VTE) in sickle cell disease (SCD) and sickle cell trait (SCT).

\begin{tabular}{|c|c|c|}
\hline Author and ref. & Study aim, design and setting & Main findings \\
\hline Stein et al..$^{65}$ & $\begin{array}{l}\text { Aim: Determine frequency and prevalence of PE and DVT. } \\
\text { Retrospective analysis of National Hospital Discharge } \\
\text { Survey comparing SCD patients } \leq 40 \text { years vs. } \\
\text { African-American patients. }\end{array}$ & $\begin{array}{l}\text { SCD patients have a high prevalence of PE }(0.44 \%) \text { compared } \\
\text { with African-Americans without SCD }(0.12 \%) \text {. DVT prevalence } \\
\text { was similar in both groups, } 0.44 \% \text { and } 0.40 \% \text {, respectively. }\end{array}$ \\
\hline Austin et al. ${ }^{137}$ & $\begin{array}{l}\text { Aim: Evaluate the incidence of VTE in individuals with SCT. } \\
\text { Case-control study of N=515 hospitalized patients } \\
\text { vs. } 555 \text { controls. }\end{array}$ & $\begin{array}{l}\text { The risk of VTE is increased approx. 2-fold among SCT } \\
\text { patients compared with controls. }\end{array}$ \\
\hline Naik et al. ${ }^{16}$ & $\begin{array}{l}\text { Aim: Define frequency and characteristics of VTE in SCD. } \\
\text { Retrospective single center study of N=404 SCD patients } \\
\text { (Sickle Cell Center for Adults-Johns Hopkins). }\end{array}$ & $\begin{array}{l}\text { VTE is common ( } 25 \% \text { ), occurring at a mean age of } 30 \text { years. } \\
\text { Sickle variants genotypes and tricuspid regurgitant jet velocity } \\
\geq 2.5 \mathrm{~m} / \mathrm{s} \text { were associated with non-catheter-related VTE. }\end{array}$ \\
\hline Seaman et al. ${ }^{18}$ & $\begin{array}{l}\text { Aim: Evaluate rates and risk factors related with } \\
\text { VTE in pregnant women with SCD. } \\
\text { Retrospective using Pennsylvania Health Care Database. }\end{array}$ & $\begin{array}{l}\text { Pregnancy-related VTE in women with SCD appeared to be } \\
1.5-5 \text { times greater than pregnancy-related VTE in the general } \\
\text { population. } \\
\mathrm{N}=212 \text { SCD pregnant women }\end{array}$ \\
\hline Naik et $a l^{6}$ & $\begin{array}{l}\text { Aim: Determine the incidence of first VTE. } \\
\text { Retrospective cohort study using prospective data from } \\
\text { the co-operative study of SCD. } \\
\mathrm{N}=1,523 \text { SCD patients } \geq 15 \text { years. }\end{array}$ & $\begin{array}{l}\text { The cumulative incidence for first VTE was } 11.3 \% \text { by } \\
\text { age } 40 \text { years. } \\
\text { Incidence of PE exceeded that of isolated DVT. } \\
\text { SCD patients with VTE had a higher mortality than those } \\
\text { without VTE. }\end{array}$ \\
\hline Folsom et al. ${ }^{19}$ & $\begin{array}{l}\text { Aim: Risk of VTE in individuals with SCT. } \\
\text { Prospective population-based cohort (1987-2011). } \\
\text { N=268 SCT middle-aged patients. }\end{array}$ & $\begin{array}{l}\text { SCT carries a 2-fold increased risk of PE but did not appear } \\
\text { to be associated with elevated DVT risk. }\end{array}$ \\
\hline Little et al. ${ }^{20}$ & $\begin{array}{l}\text { Aim: Determine risk of VTE in individuals with SCT. } \\
\text { Prospective cohort study with nested case-control design. } \\
\mathrm{N}=6,758\end{array}$ & $\begin{array}{l}\text { SCT individuals had a higher risk of VTE, particularly PE, } \\
\text { compared with non-carriers. }\end{array}$ \\
\hline Brunson et al. ${ }^{7}$ & $\begin{array}{l}\text { Aim: Evaluate VTE incidence in SCD. } \\
\text { Retrospective study using California administrative database. } \\
\mathrm{N}=6,237 \text { SCD patients. }\end{array}$ & $\begin{array}{l}\text { The cumulative incidence of VTE was high (11.2\%) in SCD } \\
\text { patients. The occurrence of VTE was associated with higher } \\
\text { mortality. }\end{array}$ \\
\hline Kumar et al..$^{22}$ & $\begin{array}{l}\text { Aim: Evaluate the VTE incidence in children with SCD. } \\
\text { Pediatric health information database. } \\
\mathrm{N}=181 \text {. }\end{array}$ & $\begin{array}{l}1.7 \% \text { developed VTE, use of a central venous catheter was } \\
\text { associated with VTE development, and VTE was associated } \\
\text { with mortality. }\end{array}$ \\
\hline Brunson et al. ${ }^{8}$ & $\begin{array}{l}\text { Aim: Determine VTE recurrence and bleeding risk in SCD } \\
\text { patients with index VTE. } \\
\text { Retrospective study using California administrative database. } \\
\text { N=877 SCD patients with an index VTE. }\end{array}$ & $\begin{array}{l}\text { The cumulative incidence of VTE recurrence was } 13.2 \% \text { and } \\
24.1 \% \text { at } 1 \text {-year and } 5 \text {-year follow-up. The cumulative } \\
\text { incidence of bleeding was } 4.9 \% \text { and } 7.9 \% \text { at } 6 \text { months and } \\
1 \text { year following an incident VTE. }\end{array}$ \\
\hline $\begin{array}{l}\text { Srisuwananukorn } \\
\text { et al. }{ }^{23}\end{array}$ & $\begin{array}{l}\text { Aim: Investigate the genetic and clinical predictors of } \\
\text { arterial and venous thrombosis in SCD. } \\
\text { Longitudinal single center cohort study. } \\
\mathrm{N}=1,193 \text { pediatric and adult SCD patients. }\end{array}$ & $\begin{array}{l}\text { VTE risk was independently associated with } \mathrm{HbSS} / \mathrm{S} \beta^{0} \\
\text { genotype, } \mathrm{HU} \text { use, lower estimated glomerular filtration rate, } \\
\text { and higher } \mathrm{Hb} \text { and WBC count. } \\
\text { THBD variants, rs } 2567617 \text { and rs } 1998081 \text { were associated } \\
\text { with thrombosis. }\end{array}$ \\
\hline
\end{tabular}

PE: pulmonary embolism; DVT: deep vein thrombosis; N: number; HU: hydroxyurea; THBD: thrombomodulin; Hb: hemoglobin;WBC: white blood cell. 
patients demonstrate abnormally elevated levels of intravascular TF that is believed to trigger activation of coagulation and pathological thrombosis. ${ }^{52-55}$ Critically, intravascular TF binding with factor VIIa activates the extrinsic pathway of coagulation by converting coagulation factor $\mathrm{X}$ to $\mathrm{Xa}$ and generating thrombin (Figure 3), which, unchecked, leads to vascular fibrin deposition. From this perspective, defining the molecular mechanisms regulating these thrombo-inflammatory processes in SCD and identifying interventions to counter vascular thrombosis is of major relevance.

\section{Cellular components of blood that facilitate thromboinflammation}

\section{Sickle red cells}

That red cells in SCD are likely to be involved in thrombus formation is supported by the relationship between hematocrit and $\mathrm{VTE}^{24}$ possibly resulting from alterations in viscosity, adhesive cellular interactions, and microvascular stasis. ${ }^{56,57}$ Studies of sickle red cells have identified numerous receptors and ligands that mediate adhesive interactions with the vessel wall, implicating their role in

A

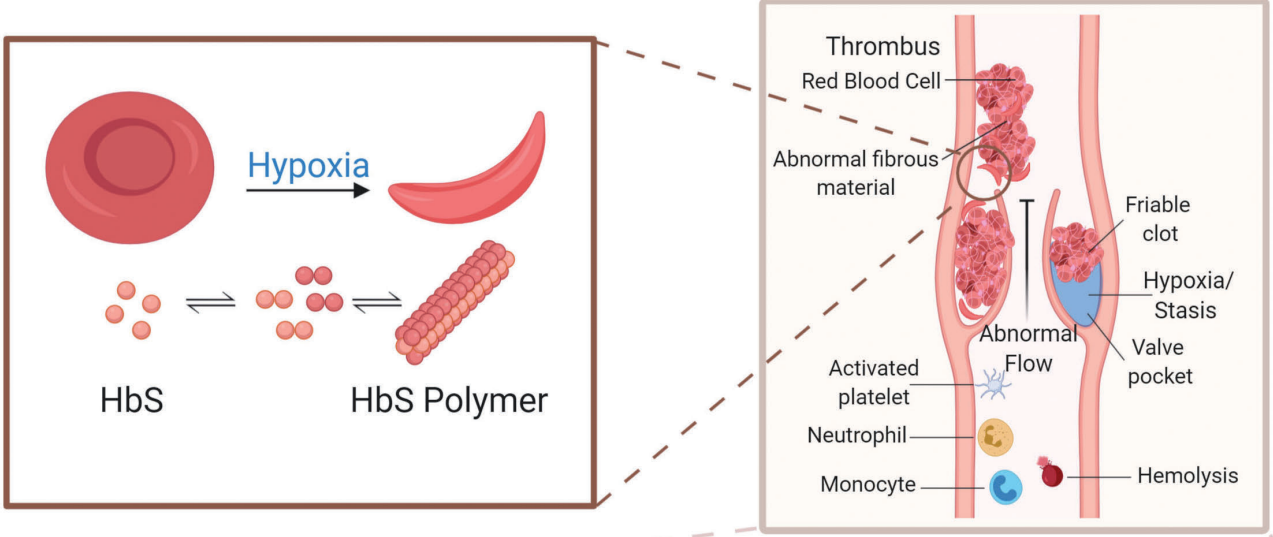

B

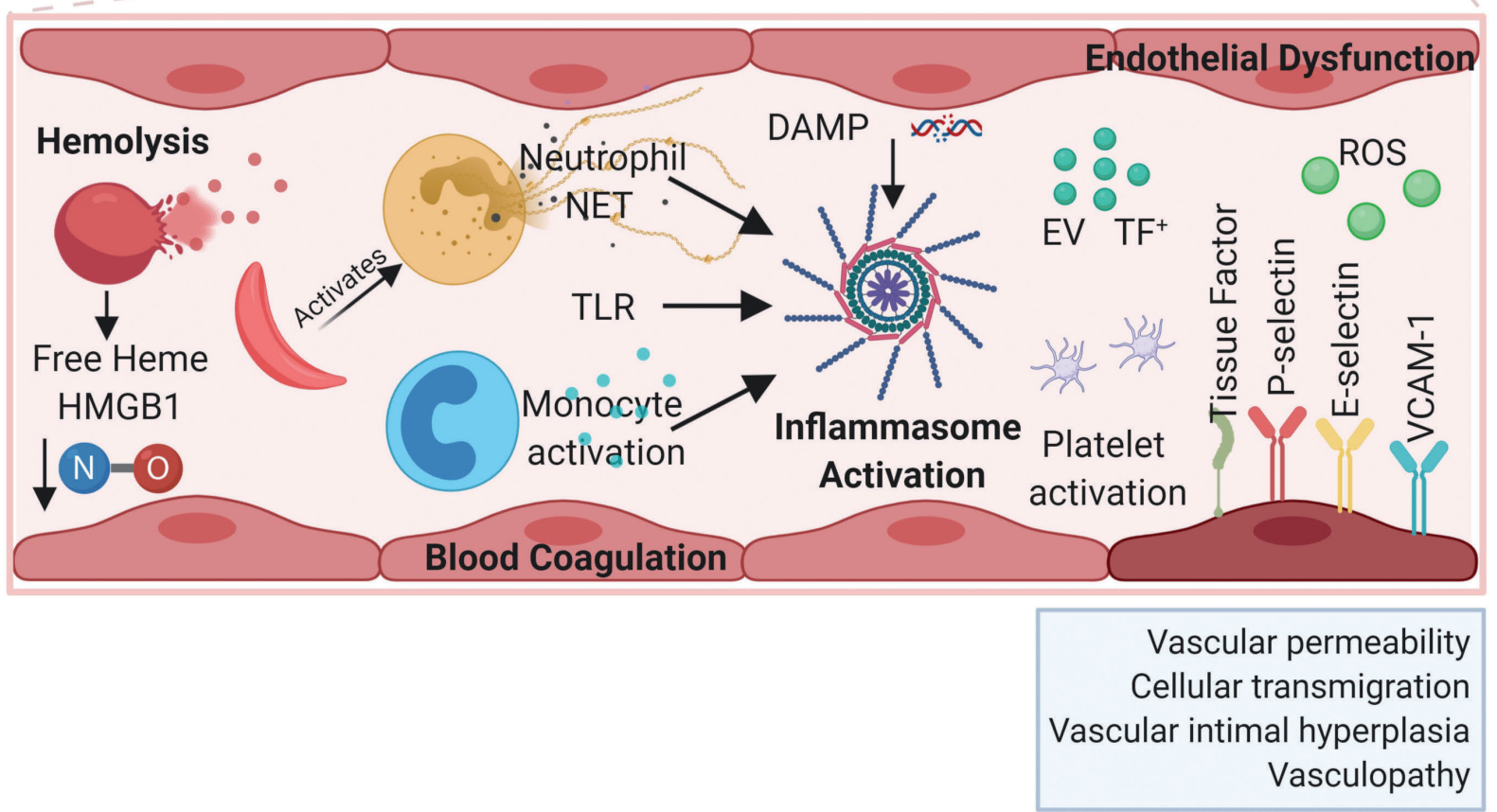

Figure 1. Sickle hemoglobin (HbS) polymerization, hemolysis and ischemia/reperfusion injury induce chronic inflammation. (A) Primary to sickle cell disease pathology is polymerization of $\mathrm{HbS}$ during red cell deoxygenation that results in sickled red cells and frequent painful vaso-occlusive crises. Hypoxia in the venous vasculature and valve pockets may worsen sickling mediated hemolysis and venous endothelial injury/inflammation. (B) Repeated sickling and unsickling episodes lead to intravascular hemolysis and release of free heme that consumes nitric oxide (NO). Sickle RBC also activate neutrophils among other cells, forming hetero and homotypic aggregates with blood cells that lead to vaso-occlusion in the post capillary venule. Endothelial damage and endothelial surface expression of adhesion and procoagulant molecules leads to transit delays increasing the potential for stasis and further sickling. Damage-associated molecular pattern (DAMP) molecules (free heme and high mobility group box 1 [HMGB1]) activate of various inflammatory pathways, e.g. NETosis, toll-like receptor (TLR) signaling, innate immune response and production of reactive oxidative species (ROS) lead to chronic inflammation. Repeated episodes of vaso-occlusive crisis (VOC) leads to ischemia followed by reperfusion mediating a well characterized injury response in the vascular endothelium. Figure created with BioRender.com. VCAM1: vascular cell adhesion molecule 1; EV TF: extracellular vesicle tissue factor; NET: neutrophil extracellular trap. 
post capillary venule occlusion (Figure 2). ${ }^{58,59}$ Elevated numbers of phosphatidylserine (PS) positive sickle red cell and red cell derived extracellular vesicles (EV) are observed in SCD patients, which correlate with markers of thrombin generation. ${ }^{55,60,61}$ In non-SCD models, venous thrombus size is impacted by localization of red cells within blood clots, which in turn is affected by fibrin network density and fibrin $\alpha$-chain crosslinking activity. ${ }^{62,63}$ Recent studies in SCD mice have shown higher amounts of fibrin deposition and red cell entrapment within the developing venous thrombus ${ }^{64}$ that are likely to impact thrombus structure and stability. These findings imply that venous clots in SCD patients and individuals with SCT are more friable and prone to embolization, possibly explaining why individuals with sickling hemoglobinopathies appear to have a higher risk of PE compared to DVT. ${ }^{6,7,19,65}$ However, in situ pulmonary thrombosis in SCD patients ${ }^{66}$ suggests heterogenous mechanisms, that may include abnormal pulmonary vascular endothelial TF expression. ${ }^{6}$

\section{Platelets}

Due to the physiological role platelets play in primary hemostasis, platelet activation probably contributes to thrombosis in SCD. For example, activated platelets in SCD can recruit leukocytes to sites of inflammation through surface P-selectin, and release prothrombotic granule contents. Besides, activated platelets form homotypic and heterotypic cell-aggregates, and platelet-neutrophil aggregates contribute to pulmonary arteriolar micro emboli. ${ }^{68-71}$ In recent studies, both murine models and SCD patients have consistently demonstrated activation of the platelet NLRP3 inflammasome, suggesting an autocrine feedback loop for IL-1 $\beta$ driven priming of innate immune and vascular endothelial cells. ${ }^{68,72}$ Moreover, solu-

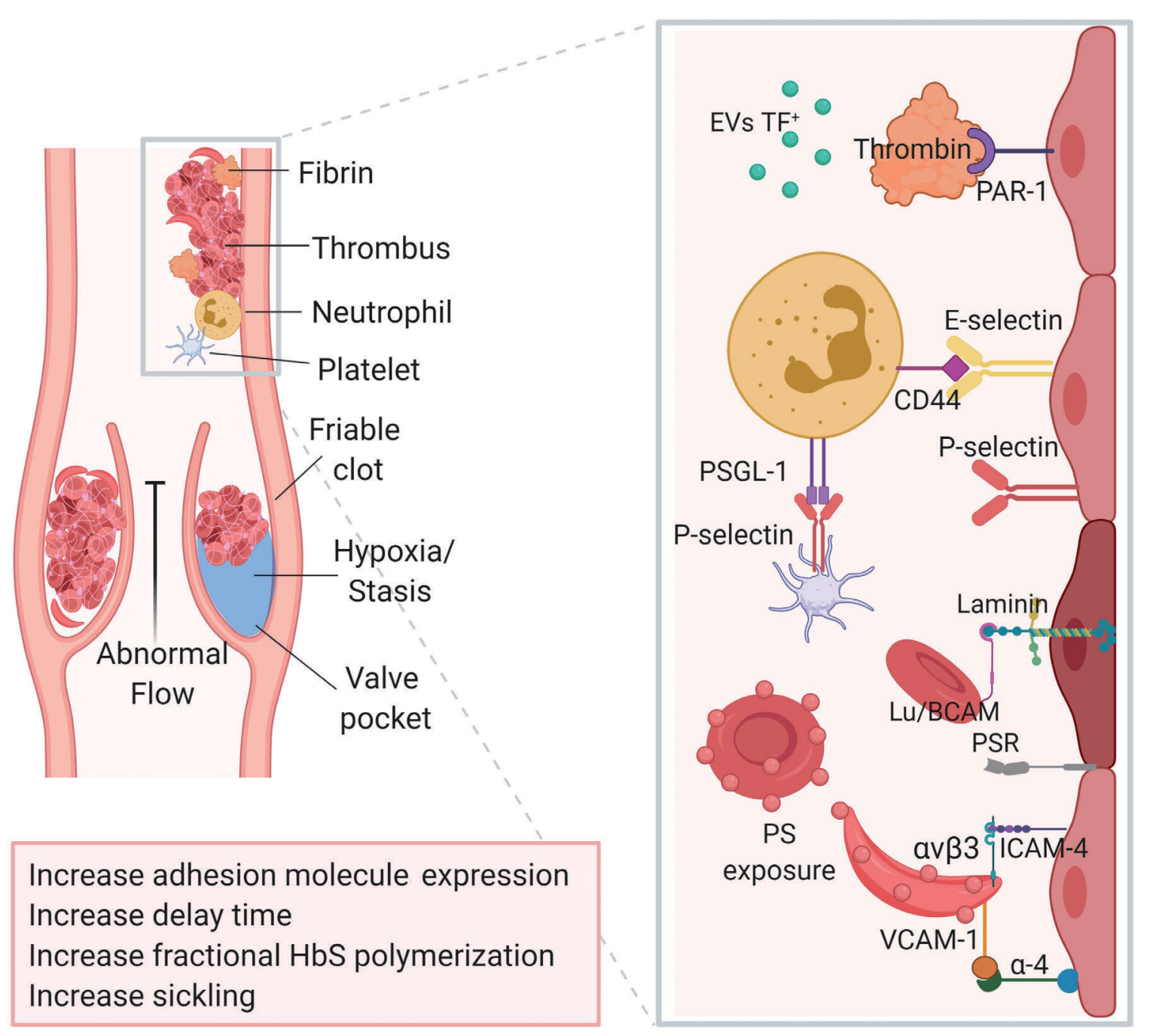

Figure 2. Inflammation and adhesion propagate stasis and contribute to fibrin deposition. Persistent inflammation leads to endothelial cell activation and endothelial dysfunction. Increased tissue factor (TF) and $\mathrm{TF}^{+}$extracellular vesicle (EV) can generate thrombin and activate coagulation. Thrombin also activates cell surface protease activating receptors (PAR), worsening endothelial inflammation and dysfunction. Abnormal surface expression of adhesion molecules (P-selectin, E-selectin and V-CAM) and platelet activation facilitate heterotypic cellular interactions. Similarly, increased heterotypic and homotypic cellular adhesion interactions mediated via cell surface ligands E-selectin/CD44, Laminin/LuBCAM, $\alpha-4$ /VCAM-1, PSR/PS etc., promote vascular stasis and favor thrombosis. Overall this prothrombotic milieu favors red cell entrapment, vascular fibrin deposition, and thrombus formation. Figure created with BioRender.com. PSR: phosphatidylserine receptor; PAR1: protease activated receptor 1; PSGL-1: P-selectin glycoprotein ligand 1; EV TF: extracellular vesicle tissue factor; ICAM-4: intercellular adhesion molecule; Lu/BCAM: Lutheran/basal cell adhesion molecule; PS: phosphatidylserine. 
ble CD40L and thrombospondin-1, two platelet-derived molecules are reportedly elevated in SCD patients with a history of ACS, ${ }^{73,74}$ which, in the light of dense platelet-rich thrombi found on autopsy in the pulmonary vasculature of over half of ACS patients, ${ }^{75}$ provides evidence for platelet-mediated thrombosis.

\section{Leukocytes}

Innate immune cells mediate SCD pathophysiology, as recently reviewed in this Journal. ${ }^{76}$ Amongst these, monocytes and neutrophils facilitate thrombotic vasculopathy by directly inducing endothelial injury and activating coagulation. Neutrophils undergo NETosis, a neutrophil defense mechanism that involves the release of NET and initiates venous thrombosis. ${ }^{77}$ In vitro studies suggest that actually cell-free DNA (cfDNA) and histones, rather than intact NET, activate coagulation, ${ }^{78}$ and while SCD patients have elevated plasma levels of cfDNA, histones and NET, ${ }^{79,80}$ no direct evidence links them with VTE development. Neutrophil-endothelial and neutrophil-platelet cross-talk, mediated via P-selectin-PSGL1 interactions are key aspects of SCD pathobiology, as evidenced by the clinical efficacy of the anti-P-selectin antibody crizanlizumab (Figure 2). ${ }^{81}$ Monocytes regulate important aspects of blood coagulation, innate immune response, reticuloen- dothelial function, and phagocytosis. Circulating $\mathrm{TF}^{+}$ monocytes and $\mathrm{TF}^{+}$monocyte EV form the major fraction of measurable blood borne TF and thus contribute meaningfully to coagulation abnormalities observed in SCD patients. ${ }^{54,55}$ Monocyte activation by heme and placental growth factor (PLGF) released from sickle red cells can stimulate the production of proinflammatory cytokines and chemokines (e.g., IL-1 $\beta$, TNF- $\alpha$, MCP-1 and MIP$1 \beta),{ }^{45,82,83}$ that in turn are capable of inducing TF gene expression. ${ }^{84}$ Lastly, frequent VOC in SCD could reduce the number of patrolling monocytes $\left(\mathrm{CD} 14^{\mathrm{low}} \mathrm{CD} 16^{+}\right)$ responsible for restoration of endothelial function ${ }^{85}$ thereby augmenting endothelial injury and dysfunction.

\section{Molecular components in blood facilitating thromboinflammation}

\section{Blood borne tissue factor}

As described above, intravascular TF expression in the setting of SCD-related endothelial damage is likely a major contributor to the hypercoagulable state of SCD; however, the role of "blood borne" TF in SCD-related thrombosis is largely unknown. ${ }^{86-89}$ Studies have shown
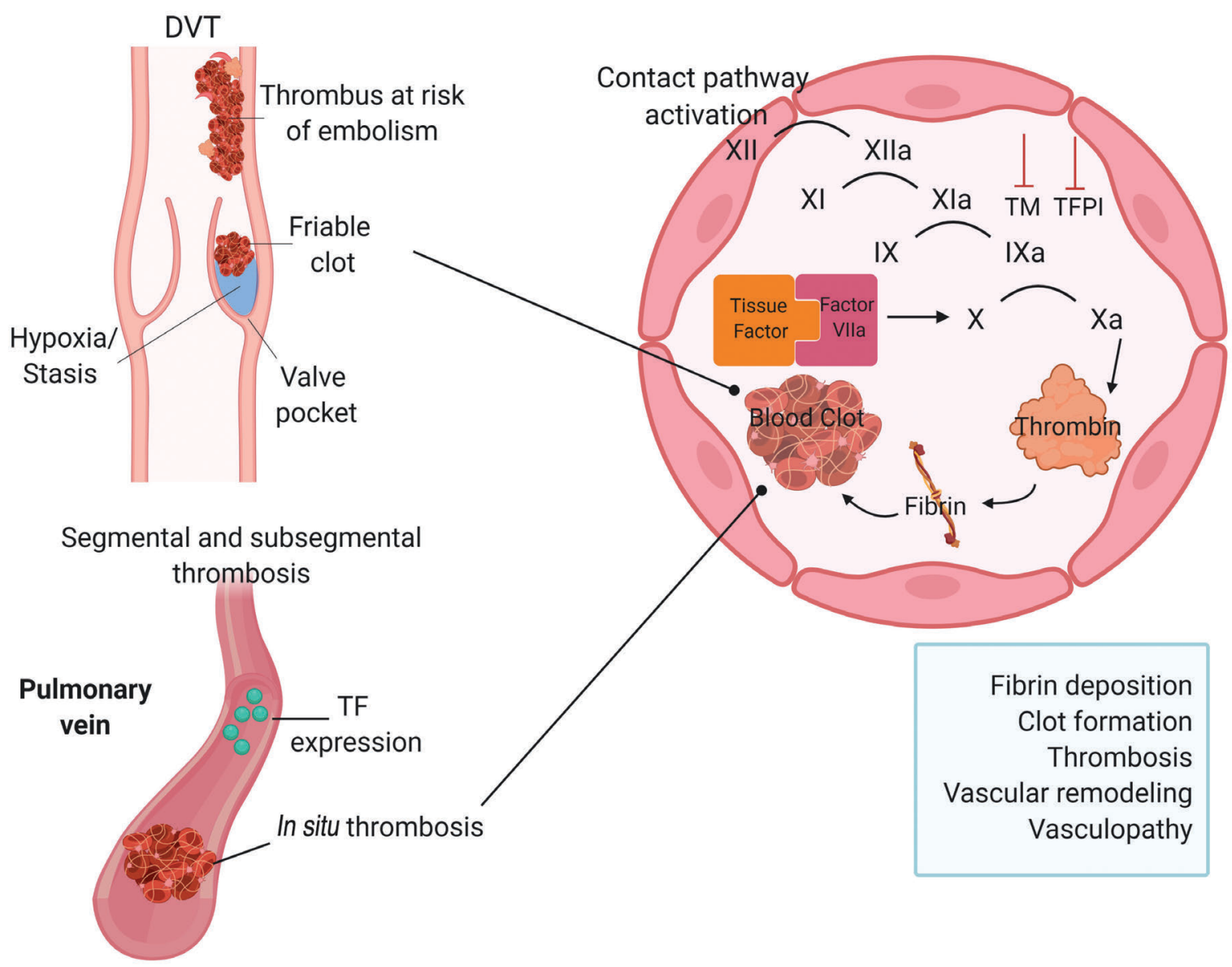

Figure 3. The TF and contact pathways activate coagulation and generate thrombin. Abnormal expression of intravascular TF in sickle cell disease (SCD), the so called "blood borne TF", triggers intravascular blood coagulation and pathological thrombosis. After binding with plasma factor VIla, TF activates the extrinsic pathway of coagulation, generating thrombin, which mediates fibrin deposition, thrombosis and vascular remodeling. Besides lowered natural anticoagulant factor levels (thrombomodulin, protein C and S) also favor thrombosis. Activation of the contact pathway of coagulation by RBC phosphatidylserine (PS) exposure, cell-derived extracellular vesicles (EV), platelet polyphosphates, cfDNA and NET also sustain thrombin generation. TF and thrombin cause chronic inflammation possibly leading to endothelial injury, vascular permeability, angiogenesis and vascular remodeling, all of which are reflected by vasculopathy. Figure created with BioRender.com. 
that SCD patients have elevated blood borne TF procoagulant activity. ${ }^{52-55,90}$ Specifically, $\mathrm{TF}^{+} \mathrm{EV}$, which are derived from monocytes and endothelial cells, have been found to be elevated in SCD patients during acute VOC. ${ }^{54}$ Although, frequent VOC in SCD has been associated with an increased risk of VTE, ${ }^{7}$ no studies have evaluated whether cell-surface TF expression or $\mathrm{TF}^{+} \mathrm{EV}$ play a direct role in initiating venous thrombosis.

Several other regulatory mechanisms could modify VTE risk in SCD, as not all SCD patients with elevated levels of blood borne TF experience pathological thrombosis. For example, inactivation of blood borne TF by tissue factor pathway inhibitor (TFPI) probably protects against pathological thrombosis, ${ }^{91}$ but TFPI antigen levels in SCD patients are found to be normal. ${ }^{53}$ Besides, the procoagulant activity of TF is under post-translational regulatory control; these mechanisms are beyond the scope of this discussion but are reviewed elsewhere. ${ }^{92}$ Regulation of TF procoagulant activity could limit overt clinical thrombosis in SCD but does not appear sufficient to inhibit TF and thrombin-mediated inflammatory vasculopathy. ${ }^{41,93}$

\section{Thrombin generation}

Activation of coagulation either through the TF or contact factor pathways leads to generation of thrombin. Thrombin, one of the most potent biological proinflammatory molecules, activates both cellular and plasmatic components of blood. These actions primarily include cleavage of factors comprising the plasma coagulation, complement and fibrinolytic cascades. In addition to converting soluble fibrinogen to insoluble fibrin, thrombin activates complement, innate immune cells, the endothelium and platelets, which in SCD mediates vascular thrombosis and vessel wall remodeling (Figure 3). .1,93 $^{41}$ Moreover, overwhelming evidence for thrombin-mediated vasculopathy is derived from elegant studies in sickle mouse models. ${ }^{40,41,94}$

In the aftermath of the initial thrombin burst generated by the TF-VIIa complex, a continuous supply of thrombin generation is required for pathological thrombosis. Thrombin generation is sustained in SCD patients even during the steady state, as demonstrated by the observation of elevated plasma levels of thrombin-anti thrombin complexes, D-dimers, and prothrombin fragment 1.2 $2^{95-97}$ and elevated in vitro thrombin generation potential..$^{98}$ The contact pathway (plasma kallikrein-kinin system) is also implicated in sustaining thrombin generation in SCD patients, ${ }^{99,100}$ and endogenous activators of the contact pathway, e.g., PS on the surface of red cells and EV, ${ }^{99,100}$ polyphosphates (polyP) released by platelets, and nucleic acids (NET or cfDNA) ${ }^{80}$ are elevated in both SCD patients and those with SCT. ${ }^{101}$ Thus, both TF and the contact pathway activation contribute to thrombin generation in SCD patients. ${ }^{15}$

\section{Canonical pathways critical to thrombosis pathophysiology}

Several concurrent inflammatory processes increase thrombotic risk in SCD. In the absence of pathogenic organisms, cell death and release of damage-associated molecular patterns (DAMP) trigger a vascular response termed "sterile inflammation". In SCD, DAMP prime the innate immune system through converging inflammatory pathways, such as TLR signaling, NETosis (see above) and activation of the inflammasome. ${ }^{43}$ Murine studies that delineate how prototypic DAMP molecules (e.g., cell-free hemoglobin and high-mobility group box 1 [HMGB1]) play a critical role in VTE pathophysiology offer major insight into the occurrence of thrombosis in SCD. ${ }^{45,80,102-105}$ As noted above, cell-free hemoglobin is proinflammatory and prothrombotic due to nitric oxide (NO) consumption, ${ }^{106}$ induction of endothelial surface $\mathrm{TF}^{107}$ and TLR4induced monocyte priming. ${ }^{45}$ Similarly, disulfide HMGB1, derived from platelets, prime the leukocyte inflammasome and induce NET, facilitating VTE development in a murine model. ${ }^{102}$ Plasma HMGB1 levels are elevated in patients with SCD, ${ }^{72,103}$ but their contribution to NET formation and VTE pathophysiology in SCD is uncertain. Murine models of intravascular hemolysis demonstrate a co-operative role for complement activation and P-selectin in mediating thrombotic injury of hepatic and renal vascular endothelium, and provide insight into how sickle hemolysis might mediate organ injury. ${ }^{104,108}$ Taken together with the findings that $\mathrm{HU}$ attenuates complement activation in SCD patients ${ }^{109}$ and the efficacy of P-selectin blockade in preventing VOC, ${ }^{81}$ it is apparent that modulating these pathways may offset microvascular thrombosis. Advancing our understanding of these complex interactions between dysregulated inflammation and coagulation processes in SCD might offer additional insights and identify new therapeutic targets to limit thrombosis, particularly VTE.

\section{Thromboinflammation, vascular injury and vasculopathy}

In addition to pathological thrombosis occurring as a result of the TF/VIIa complex (as described above), cell surface TF expression leads to inflammation. TF-mediated inflammation occurs either via the effects of downstream coagulation proteases (see above) on other vascular endothelial and blood cells ${ }^{94}$ or intracellularly, via its cytoplasmic tail. ${ }^{88}$ Thrombin's subsequent interaction with endothelial cell surface protease activating receptors (PAR) accentuates vascular endothelial inflammation in SCD. ${ }^{110}$ Continued activation of coagulation, initially triggered by TF, likely occurs via EV and PS positive red cells in circulating blood, that by virtue of their surface PS content support the assembly of tenase and prothrombinase complexes $^{111}$ (Figures 1 and 3). Moreover, in addition to procoagulant effects exerted by surface TF and PS, EV display membrane surface antigens, e.g., P-selectin, that engage with ligands to enhance production of $\mathrm{TF}^{+} \mathrm{EV}^{112,113}$ and reactive oxygen species (ROS). ${ }^{105}$ Splenic hypofunction and diminished reticuloendothelial clearance in SCD lead to accumulation of prothrombotic mediators, i.e., $\mathrm{PS}^{+}$red cells, red cell derived $\mathrm{EV}$ and leukocyte/endothelial derived $\mathrm{TF}^{+}$ EV. In venous vascular beds prone to stasis and hypoxia, accumulation of procoagulant factors may overwhelm anticoagulant defenses and lead to pathological thrombosis.

A likely sequence of events may include the following: (i) sluggish cell transit through the post capillary venules which may increase "delay time"114 augmenting the fraction of polymerized $\mathrm{HbS}$; and (ii) formation of hetero and homotypic cellular aggregates that, coupled with 
increased endothelial cell adherence promote stasis, lead to further red cell sickling, vaso-occlusion, and ischemic crisis. These sickling cycles promote repeated vascular injury, vasomotor dysfunction, chronic inflammation and vasculopathy in patients with SCD. ${ }^{115,116}$ Moreover, the cumulative effects of stasis, altered rheology, vascular fibrin deposition and chronic inflammation ultimately leads to chronic vasculopathy ${ }^{47}$ and characterizes the multiorgan failure observed in SCD patients. ${ }^{117}$ Vasculopathy in patients experiencing DVT is reflected by the onset of post-thrombotic syndrome, valvular venous insufficiency or leg ulceration and, in patients experiencing PE, by the onset of chronic thromboembolic pulmonary hypertension (CTEPH). ${ }^{118}$ The sickle prothrombotic state and resulting VTE, therefore, results in considerable cardiopulmonary morbidity and mortality.

\section{Managing venous thrombosis in sickle cell disease}

Because prospective trials of anticoagulation in VTE have not, to our knowledge, included subjects with SCD, recommendations on VTE management in SCD patients generally rely on clinical guidelines developed for the general population. ${ }^{119}$ It should be noted that, while clinical probability scores and laboratory biomarkers help determine the pretest probability of VTE in the general population, ${ }^{120}$ there is no evidence to support this approach in SCD patients. In addition, the lack of prospective primary prevention and/or management studies of VTE in either pregnant women with SCD or high-risk SCD patients leads to over-reliance on data from prospective studies of VTE in individuals with inherited prothrombotic states. ${ }^{39}$

Patients with SCD who are suspected of having VTE should undergo compression ultrasound Dopplers for DVT and multidetector computerized tomographic pulmonary angiography and/or radionuclide scanning (ventilation-perfusion [V/O] scanning) for PE. ${ }^{39}$ Subsequent management of confirmed VTE occurs in two phases: (i) "active treatment" consisting of therapeutic dose anticoagulation for three months to suppress the acute episode of thrombosis; and (ii) "secondary prevention" consisting of therapeutic or prophylactic dose anticoagulation for an indefinite duration to prevent new VTE episodes unrelated to the index event. ${ }^{39}$

According to ACCP guidelines, in patients with a low risk of bleeding, a risk of recurrent VTE of $>13 \%$ in the first year results in a strong recommendation and a risk of $8-13 \%$ in the first year results in a weak recommendation for indefinite anticoagulation therapy. ${ }^{119}$ Prior cohort studies have suggested that the VTE recurrence rate in SCD ranges from approximately $25-40 \%$, 8,16 although anticoagulation adherence data are generally lacking in these studies. Nonetheless, the high VTE recurrence rate in SCD patients appears to justify indefinite anticoagulation as an efficacious secondary prevention strategy, especially in patients with unprovoked or recurrent provoked thrombosis. $^{121}$

Even SCD patients with less severe disease have high VTE recurrence rates (18\% at 5 years) with no difference according to whether the incident event occurred within or $>90$ days after hospitalization, ${ }^{6,8}$ suggesting that most patients are likely to benefit from secondary prevention. However, caution may be warranted, as clinical and plas- ma biomarkers that reliably predict VTE recurrence in SCD patients have not been identified to guide decision making in this subgroup, unlike in the general population with unprovoked VTE. ${ }^{120}$ When considering indefinite anticoagulation therapy, the perceived risk/benefit ratio influences both patients and physicians alike. Population-based studies reveal a non-linear bleeding risk associated with indefinite anticoagulation, which increases with age, disease comorbidity, polypharmacy, and renal insufficiency. ${ }^{28}$ In addition, a high incidence of bleeding, particularly gastrointestinal bleeding, has been noted in SCD patients exposed to anticoagulation. ${ }^{122}$ Thus, evaluating common risk factors, such as prior bleeding episodes, severe anemia, thrombocytopenia, renal and hepatic failure, use of antiplatelet and NSAID, can inform decisions about both anticoagulant choice and duration of therapy in SCD. Moreover, assessing for central nervous system (CNS) vasculopathy (Moya Moya disease and aneurysmal dilatation of cranial vessels), which can increase the risk of intracranial hemorrhage even in the absence of anticoagulation, is important.

The primary goal of anticoagulation is to limit and resolve thrombosis with minimal perturbation of hemostasis. Among all the available anticoagulants, the DOAC come closest to achieving this goal, although the risk of bleeding is not completely eliminated. For instance, in patients with VTE and no active cancer, a meta-analysis revealed that DOAC were at least as effective as warfarin but reduced the risk of major bleeding only by $40 \%$ and did not completely eliminate it. ${ }^{123}$ Prospective evidence from a meta-analysis of two randomized trials of DOAC in cancer-associated VTE reported 6-month outcomes of improved efficacy with DOAC compared to dalteparin (relative risk [RR] of recurrent VTE: 0.65; 95\% confidence interval [CI]: 0.42-1.01), but the risk of bleeding was greatly increased (major bleeding RR: 1.74; 95\%CI: 1.05-2.88 and non-major bleeding RR: 2.31; 95\%CI: 0.85-6.28). ${ }^{124}$ In patients with SCD-associated VTE anticoagulation associated bleeding is particularly evident. Retrospective analysis of anticoagulation for SCD-associated VTE reveals a cumulative bleeding incidence of $4.9 \%(95 \% \mathrm{CI}: 3.5-6.4 \%)$ at 6 months and $7.9 \%$ (95\% CI: 6.2-9.8\%) at 1 year. ${ }^{8}$ In patients with severe SCD, the bleeding risk was greatest (HR: 1.61; 95\% CI: 1.11-2.35). ${ }^{8}$ Similarly, smaller retrospective studies indicate that all anticoagulants have an increased bleeding risk, with DOAC having the least risk. ${ }^{23,125,126}$ In spite of these advantages, the exact role for DOAC in the management of VTE in SCD patients is not clear.

\section{Perspectives}

Dysregulation of inflammatory and coagulation pathways, both during the steady state and during VOC, are an important hallmark of the sickle prothrombotic state. They appear to be directly associated with the development of thrombotic complications, such as VTE, which is known to increase SCD morbidity and mortality. Given the important role of coagulation in SCD, it is valid to expect that sickle specific therapies seeking to reduce inflammation and coagulation biomarkers would have an effect on lowering thrombosis incidence. Although some sickle specific therapies (HU and transfusion) are associated with reduced arterial thrombosis risk, ${ }^{13}$ surprisingly few studies have evaluated the effect of these therapies 
on venous thrombosis. HU use was associated with reduced biochemical indicators of coagulation activation in SCD patients ${ }^{127}$ when compared with non-users, and led to lowered cfDNA levels. ${ }^{79}$ In myeloproliferative neoplasms, prospective studies of HU have shown a reduction in thrombosis biomarkers and thrombosis risk, ${ }^{128}$ but the lack of similar studies in SCD makes this area a research priority. For instance, targeting P-selectin can diminish heterotypic cellular adhesive interactions (see above) and may prevent vascular endothelial cell activation and injury. Considering its mild adverse event profile, ${ }^{81,129}$ crizanlizumab could possibly lower the incidence of thrombosis in SCD without compromising hemostasis.

Given the diverse pathophysiological processes involved in SCD, it is important to narrow down key thrombo-inflammatory pathways involved in VTE pathobiology and design interventions specifically targeting venous thrombosis. From this viewpoint, several trials evaluating the effects on anticoagulants on modulating the vascular pathobiology of SCD are either ongoing or completed (Table 2). However, concerns regarding study design and implementation limit the interpretability of several of these studies, emphasizing the challenges faced by clinical investigation in this field. Nonetheless, implementation of a double-blinded, randomized, placebo controlled trial of prasugrel in children with SCD ${ }^{130}$ demonstrates feasibility of rigorous scientific experimentation in this population, and provides hope for future efficacy studies of thrombosis endpoints.

Because traditional anticoagulation for VTE in the general population and in SCD patients is associated with increased bleeding, the development of safer anticoagulant treatments is of considerable importance. Besides, as indicated above, even DOAC fail to suppress TF-mediated inflammation or prevent chronic organ dysfunction in $\mathrm{SCD},{ }^{41}$ suggesting the need for novel therapies. Targeting coagulation factors involved in SCD pathobiology (specifically TF and contact pathway components, e.g.,
FXII and FXI) would appear to have a lowered bleeding risk, especially those that are not involved in physiological hemostasis, i.e., contact pathway factors. ${ }^{131}$ For example, anti-XI therapy is both safe and efficacious for VTE prevention in the general population ${ }^{132}$ but this approach is untested in SCD. Moreover, as TF plays an important role in physiological hemostasis, therapeutic agents that inhibit TF-mediated inflammation while sparing TF-procoagulant activity are worth developing. Finally, drugs that target post-translational mechanisms regulating TF procoagulant activity, e.g., annexins or thiol-disulfide exchange inhibitors, ${ }^{92}$ could prevent pathological thrombosis.

Selecting drugs with a demonstrably lower propensity for bleeding is another approach to maximize anti-thrombotic efficacy in SCD without altering hemostasis. Aspirin, with its low bleeding risk, antithrombotic efficacy for secondary prevention of VTE, ${ }^{133}$ and proven safety in SCD may have an important thromboprophylaxis role. Statins reduce markers of hypercoagulability in subjects with unprovoked VTE after cessation of anticoagulation treatment, ${ }^{134}$ reduce abnormal pulmonary vascular TF expression in SCD mice, ${ }^{7}$ and are generally safe in SCD patients, ${ }^{135}$ providing a rationale for their further investigation in VTE thromboprophylaxis. Canakinumab, an IL-1 $\beta$ antagonist, is associated with a reduction in all-cause mortality from atherothrombotic coronary artery disease, largely via its anti-inflammatory effects. ${ }^{136}$ Elevated IL-1 $\beta$ levels and dysregulated inflammatory pathways in SCD patients, along with the relative safety of canakinumab in children with SCD (clinicaltrials.gov identifier: NCT02961218), provide a compelling rationale for testing this agent. Evaluating these therapies in the setting of controlled clinical trials would demonstrate their potential role for secondary VTE prevention in SCD.

In spite of the advances in treatment and prevention, venous thrombosis profoundly impacts chronic organ dysfunction and mortality in patients with SCD. Major scientific advances have furthered our understanding of

Table 2. Recently conducted or ongoing trials of anticoagulant therapies in sickle cell disease.

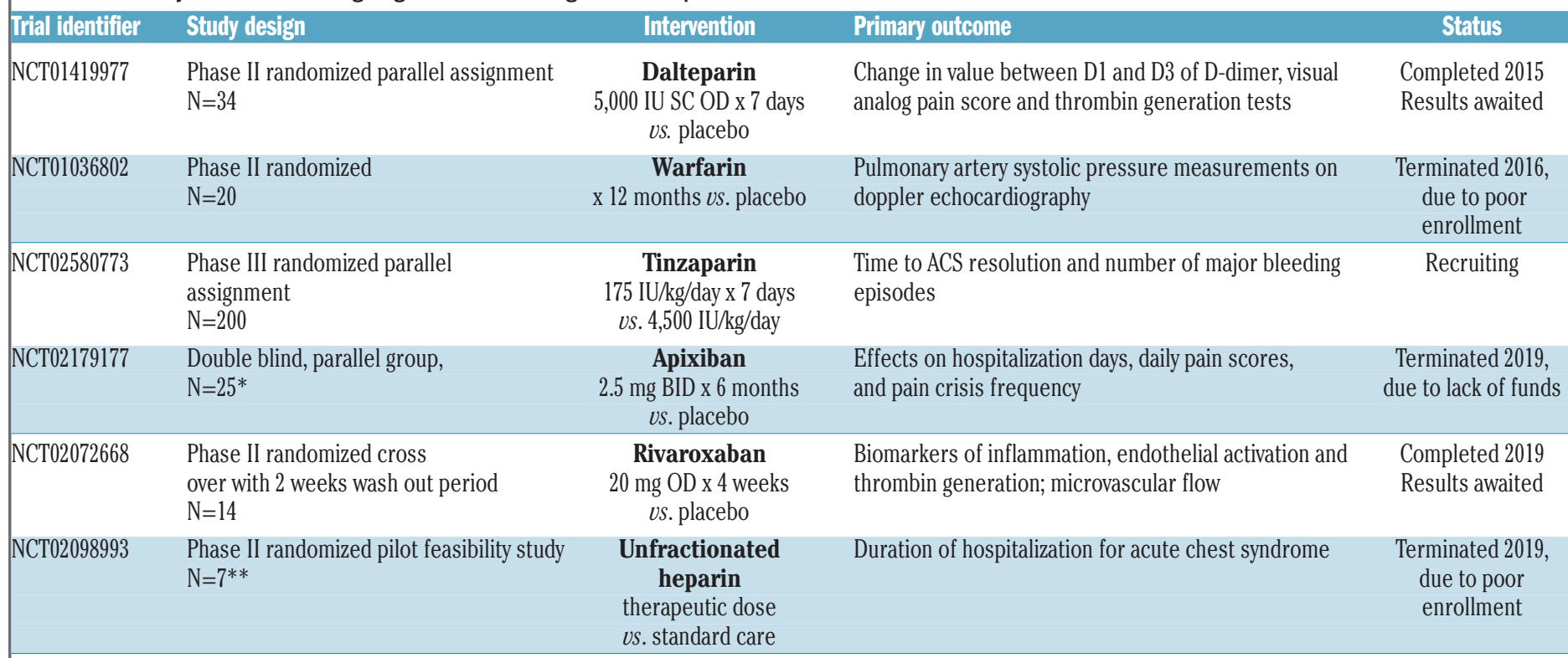

SC: subcutaneous; OD: once a day; D: day; ACS: acute chest syndrome. * $\mathrm{N}=16$ recruited at study termination. ${ }^{*}$ Actual enrollment prior to termination. 
the vascular pathobiology of SCD and led to the development of novel therapeutic agents optimal for clinical investigation. Conducting effective preventative and treatment studies to reduce VTE in SCD and establishing the scientific evidence base to guide appropriate management has therefore become a research priority. The design of these studies should include endpoints that account for simultaneous effects on anti-thrombotic efficacy and harm due to bleeding.

\section{Acknowledgement}

This work was supported by the Intramural Research Program of the National Heart, Lung, and Blood Institute, National Institutes of Health.

\section{References}

1. Tisdale JF, Thein SL, Eaton WA. Treating sickle cell anemia. Science. 2020;367 (6483):1198-1199.

2. Benz EJ Jr, Mondoro TH, Gibbons GH. Accelerating the science of SCD therapies-is a cure possible? JAMA. 2019 Aug 8. [Epub ahead of print

3. Collins FS. Curing HIV and sickle cell falls short if the most vulnerable populations are left out. Fortune. New York: Fortune Media IP Limited; 2020.

4. Adams RJ, McKie VC, Hsu L, et al. Prevention of a first stroke by transfusions in children with sickle cell anemia and abnormal results on transcranial Doppler ultrasonography. N Engl J Med. 1998;339(1):5-11.

5. Ohene-Frempong K, Weiner SJ, Sleeper LA, et al. Cerebrovascular accidents in sickle cell disease: rates and risk factors. Blood. 1998;91(1):288-294.

6. Naik RP, Streiff MB, Haywood C Jr, et al. Venous thromboembolism incidence in the Cooperative Study of Sickle Cell Disease. J Thromb Haemost. 2014;12(12):2010-2016.

7. Brunson A, Lei A, Rosenberg AS, et al. Increased incidence of VTE in sickle cell disease patients: risk factors, recurrence and impact on mortality. Br J Haematol. 2017; 178(2):319-326.

8. Brunson A, Keegan T, Mahajan A, et al. High incidence of venous thromboembolism recurrence in patients with sickle cell disease. Am J Hematol. 2019;94(8):862-870.

9. Yawn BP, Buchanan GR, Afenyi-Annan AN, et al. Management of sickle cell disease: summary of the 2014 evidence-based report by expert panel members. JAMA. 2014;312(10):1033-1048.

10. Conran N, De Paula EV. Thromboinflammatory mechanisms in sickle cell disease-challenging the hemostatic balance. Haematologica. 2020;105(10):23802390.

11. Telen MJ, Malik P, Vercellotti GM. Therapeutic strategies for sickle cell disease: towards a multi-agent approach. Nat Rev Drug Discov. 2019;18(2):139-158.

12. Matte $\mathrm{A}$, Cappellini MD, Iolascon $\mathrm{A}$, et al. Emerging drugs in randomized controlled trials for sickle cell disease: are we on the brink of a new era in research and treatment? Expert Opin Investig Drugs. 2020;29(1):23-31.

13. Kassim AA, Galadanci NA, Pruthi S, et al. How I treat and manage strokes in sickle cell disease. Blood. 2015;125(22):3401-3410.

14. Wun T, Brunson A. Sickle cell disease: an inherited thrombophilia. Hematology Am Soc Hematol Educ Program. 2016;2016(1): 640-647.

15. Noubouossie D, Key NS, Ataga KI. Coagulation abnormalities of sickle cell disease: relationship with clinical outcomes and the effect of disease modifying therapies.
Blood Rev. 2016;30(4):245-256.

16. Naik RP, Streiff MB, Haywood C Jr, et al. Venous thromboembolism in adults with sickle cell disease: a serious and under-recognized complication. Am J Med. 2013;126(5): 443-449.

17. James AH, Jamison MG, Brancazio LR, et al. Venous thromboembolism during pregnancy and the postpartum period: incidence, risk factors, and mortality. Am J Obstet Gynecol. 2006;194(5):1311-1315

18. Seaman CD, Yabes J, Li J, et al. Venous thromboembolism in pregnant women with sickle cell disease: a retrospective database analysis. Thromb Res. 2014;134(6):12491252.

19. Folsom AR, Tang W, Roetker NS, et al. Prospective study of sickle cell trait and venous thromboembolism incidence. J Thromb Haemost. 2015;13(1):2-9.

20. Little I, Vinogradova Y, Orton E, et al. Venous thromboembolism in adults screened for sickle cell trait: a populationbased cohort study with nested case-control analysis. BMJ Open. 2017;7(3):e012665.

21. Ogunsile FJ, Naik R, Lanzkron S. Overcoming challenges of venous thromboembolism in sickle cell disease treatment. Expert Rev Hematol. 2019;12(3):173-182.

22. Kumar R, Stanek J, Creary S, et al. Prevalence and risk factors for venous thromboembolism in children with sickle cell disease: an administrative database study. Blood Adv. 2018;2(3):285-291.

23. Srisuwananukorn A, Raslan R, Zhang X, et al. Clinical, laboratory, and genetic risk factors for thrombosis in sickle cell disease. Blood Adv. 2020;4(9):1978-1986.

24. Yu TT, Nelson J, Streiff MB, et al. Risk factors for venous thromboembolism in adults with hemoglobin SC or Sbeta(+) thalassemia genotypes. Thromb Res. 2016;141:35-38.

25. Lettre G, Sankaran VG, Bezerra MA, et al. DNA polymorphisms at the BCL11A, HBS1L-MYB, and beta-globin loci associate with fetal hemoglobin levels and pain crises in sickle cell disease. Proc Natl Acad Sci U S A. 2008;105(33):11869-11874.

26. Raffield LM, Ulirsch JC, Naik RP, et al. Common alpha-globin variants modify hematologic and other clinical phenotypes in sickle cell trait and disease. PLoS Genet. 2018;14(3):e1007293.

27. Thein SL, Menzel S, Peng X, et al. Intergenic variants of HBS1L-MYB are responsible for a major quantitative trait locus on chromosome 6q23 influencing fetal hemoglobin levels in adults. Proc Natl Acad Sci U S A. 2007;104(27):11346-11351.

28. Kearon C, Akl EA. Duration of anticoagulant therapy for deep vein thrombosis and pulmonary embolism. Blood. 2014;123(12): 1794-1801.

29. Zakai NA, McClure LA, Judd SE, et al. Racial and regional differences in venous thromboembolism in the United States in 3 cohorts. Circulation. 2014;129(14):1502-
1509.

30. Zimmerman SA, Ware RE. Inherited DNA mutations contributing to thrombotic complications in patients with sickle cell disease. Am J Hematol. 1998;59(4):267-272.

31. Zimmerman SA, Howard TA, Whorton MR, et al. Thrombophilic DNA mutations as independent risk factors for stroke and avascular necrosis in sickle cell anemia. Hematology. 2001;6(5):347-353.

32. Heit JA, Armasu SM, McCauley BM, et al. Identification of unique venous thromboembolism-susceptibility variants in AfricanAmericans. Thromb Haemost. 2017;117(4): 758-768.

33. Lin F, Blake DL, Callebaut I, et al. MAN1, an inner nuclear membrane protein that shares the LEM domain with lamina-associated polypeptide 2 and emerin. J Biol Chem. 2000;275(7):4840-4847.

34. Bourgeois B, Gilquin B, Tellier-Lebegue C, et al. Inhibition of TGF-beta signaling at the nuclear envelope: characterization of interactions between MAN1, Smad2 and Smad3, and PPM1A. Sci Signal. 2013;6(280):ra49.

35. Nagai Y, Shimazu R, Ogata $H$, et al. Requirement for $\mathrm{MD}-1$ in cell surface expression of RP105/CD180 and B-cell responsiveness to lipopolysaccharide. Blood. 2002;99(5):1699-1705.

36. Ortiz-Suarez ML, Bond PJ. The structural basis for lipid and endotoxin binding in RP105-MD-1, and consequences for regulation of host lipopolysaccharide sensitivity. Structure. 2016;24(1):200-211

37. Reitsma PH, Rosendaal FR. Activation of innate immunity in patients with venous thrombosis: the Leiden Thrombophilia Study. J Thromb Haemost. 2004;2(4):619622 .

38. Perner F, Perner C, Ernst T, et al. Roles of JAK2 in aging, inflammation, hematopoiesis and malignant transformation. Cells. 2019;8(8):854.

39. Shet AS, Wun T. How I diagnose and treat venous thromboembolism in sickle cell disease. Blood. 2018;132(17):1761-1769.

40. Ansari J, Gavins FNE. Ischemia-reperfusion injury in sickle cell disease: from basics to therapeutics. Am J Pathol. 2019;189(4):706718.

41. Sparkenbaugh E, Pawlinski R. Prothrombotic aspects of sickle cell disease. J Thromb Haemost. 2017;15(7):1307-1316.

42. Ataga KI, Moore CG, Hillery CA, et al. Coagulation activation and inflammation in sickle cell disease-associated pulmonary hypertension. Haematologica. 2008;93(1): 20-26.

43. Conran N, Belcher JD. Inflammation in sickle cell disease. Clin Hemorheol Microcirc. 2018;68(2-3):263-299.

44. Hebbel RP. Ischemia-reperfusion injury in sickle cell anemia: relationship to acute chest syndrome, endothelial dysfunction, arterial vasculopathy, and inflammatory pain. Hematol Oncol Clin North Am. 
2014;28(2):181-198.

45. Belcher JD, Chen C, Nguyen J, et al. Heme triggers TLR4 signaling leading to endothelial cell activation and vaso-occlusion in murine sickle cell disease. Blood. 2014;123(3):377-390.

46. Zhang D, Xu C, Manwani D, et al. Neutrophils, platelets, and inflammatory pathways at the nexus of sickle cell disease pathophysiology. Blood. 2016;127(7):801809

47. Sundd P, Gladwin MT, Novelli EM. Pathophysiology of sickle cell disease. Annu Rev Pathol. 2019;14:263-292.

48. Mendonca R, Silveira AA, Conran N. Red cell DAMPs and inflammation. Inflamm Res. 2016;65(9):665-678.

49. Lawson CA, Yan SD, Yan SF, et al. Monocytes and tissue factor promote thrombosis in a murine model of oxygen deprivation. J Clin Invest. 1997;99(7):17291738.

50. Yan SF, Zou YS, Gao Y, et al. Tissue factor transcription driven by Egr-1 is a critical mechanism of murine pulmonary fibrin deposition in hypoxia. Proc Natl Acad Sci U S A. 1998;95(14):8298-8303.

51. Houston P, Dickson MC, Ludbrook V, et al. Fluid shear stress induction of the tissue factor promoter in vitro and in vivo is mediated by Egr-1. Arterioscler Thromb Vasc Biol. 1999;19(2):281-289.

52. Solovey A, Gui L, Key NS, et al. Tissue factor expression by endothelial cells in sickle cell anemia. J Clin Invest. 1998;101(9):18991904.

53. Key NS, Slungaard A, Dandelet L, et al. Whole blood tissue factor procoagulant activity is elevated in patients with sickle cell disease. Blood. 1998:91(11):4216-4223.

54. Shet AS, Aras O, Gupta K, et al. Sickle blood contains tissue factor-positive microparticles derived from endothelial cells and monocytes. Blood. 2003;102(7):2678-2683.

55. Ragab SM, Soliman MA. Tissue factor-positive monocytes expression in children with sickle cell disease: clinical implication and relation to inflammatory and coagulation markers. Blood Coagul Fibrinolysis. 2016;27(8):862-869.

56. Vichinsky EP. Current issues with blood transfusions in sickle cell disease. Semin Hematol. 2001;38(1 Suppl 1):14-22.

57. Connes P, Alexy T, Detterich J, et al. The role of blood rheology in sickle cell disease. Blood Rev. 2016;30(2):111-118.

58. Colin Y, Le Van Kim C, El Nemer W. Red cell adhesion in human diseases. Curr Opin Hematol. 2014;21(3):186-192.

59. Goel MS, Diamond SL. Adhesion of normal erythrocytes at depressed venous shear rates to activated neutrophils, activated platelets, and fibrin polymerized from plasma. Blood. 2002;100(10):3797-3803

60. Setty BN, Rao AK, Stuart MJ. Thrombophilia in sickle cell disease: the red cell connection. Blood. 2001;98(12):32283233.

61. van Beers EJ, Schaap MC, Berckmans RJ, et al. Circulating erythrocyte-derived microparticles are associated with coagulation activation in sickle cell disease. Haematologica. 2009;94(11):1513-1519.

62. Aleman MM, Byrnes JR, Wang JG, et al. Factor XIII activity mediates red blood cell retention in venous thrombi. J Clin Invest. 2014;124(8):3590-3600

63. Byrnes JR, Wolberg AS. Red blood cells in thrombosis. Blood. 2017:130(16):1795-1799.

64. Faes C, Ilich A, Sotiaux A, et al. Red blood cells modulate structure and dynamics of venous clot formation in sickle cell disease. Blood. 2019;133(23):2529-2541.

65. Stein PD, Beemath A, Meyers FA, et al. Deep venous thrombosis and pulmonary embolism in hospitalized patients with sickle cell disease. Am J Med. 2006;119(10):897.

66. Adedeji MO, Cespedes J, Allen K, et al. Pulmonary thrombotic arteriopathy in patients with sickle cell disease. Arch Pathol Lab Med. 2001;125(11):1436-1441.

67. Solovey A, Kollander R, Shet A, et al. Endothelial cell expression of tissue factor in sickle mice is augmented by hypoxia/reoxygenation and inhibited by lovastatin. Blood. 2004;104(3):840-846.

68. Vats R, Brzoska T, Bennewitz MF et al. Platelet extracellular vesicles drive inflammasome-IL-1beta-dependent lung injury in sickle cell disease. Am J Respir Crit Care Med. 2020;201(1):33-46.

69. Wun T, Paglieroni T, Field CL, et al. Plateleterythrocyte adhesion in sickle cell disease. Investig Med. 1999;47(3):121-127.

70. Wun T, Cordoba M, Rangaswami A, et al. Activated monocytes and platelet-monocyte aggregates in patients with sickle cell disease. Clin Lab Haematol. 2002;24(2):81-88.

71. Polanowska-Grabowska R, Wallace K, Field JJ, et al. P-selectin-mediated platelet-neutrophil aggregate formation activates neutrophils in mouse and human sickle cell disease. Arterioscler Thromb Vasc Biol. 2010;30(12):2392-2399.

72. Vogel S, Arora T, Wang X, et al. The platelet NLRP3 inflammasome is upregulated in sickle cell disease via HMGB1/TLR4 and Bruton tyrosine kinase. Blood Adv. 2018;2(20):2672-2680.

73. Novelli EM, Little-Ihrig L, Knupp HE, et al. Vascular TSP1-CD47 signaling promotes sickle cell-associated arterial vasculopathy and pulmonary hypertension in mice. Am Physiol Lung Cell Mol Physiol. 2019;316(6):L1150-L1164

74. Garrido VT, Sonzogni L, Mtatiro SN, et al. Association of plasma CD40L with acute chest syndrome in sickle cell anemia. Cytokine. 2017;97:104-107.

75. Anea CB, Lyon M, Lee IA, et al. Pulmonary platelet thrombi and vascular pathology in acute chest syndrome in patients with sickle cell disease. Am J Hematol. 2016;91(2):173178.

76. Allali S, Maciel TT, Hermine O, et al. Innate immune cells, major protagonists of sickle cell disease pathophysiology. Haematologica. 2020;105(2):273-283.

77. Thalin C, Hisada Y, Lundstrom S, et al. Neutrophil extracellular traps: villains and targets in arterial, venous, and cancer-associated thrombosis. Arterioscler Thromb Vasc Biol. 2019;39(9):1724-1738.

78. Noubouossie DF, Whelihan MF, Yu YB, et al. In vitro activation of coagulation by human neutrophil DNA and histone proteins but not neutrophil extracellular traps. Blood. 2017;129(8):1021-1029.

79. Ulug P, Vasavda N, Kumar R, et al. Hydroxyurea therapy lowers circulating DNA levels in sickle cell anemia. Am J Hematol. 2008;83(9):714-716.

80. Chen G, Zhang D, Fuchs TA, et al. Hemeinduced neutrophil extracellular traps contribute to the pathogenesis of sickle cell disease. Blood. 2014;123(24):3818-3827.

81. Ataga KI, Kutlar A, Kanter J, et al Crizanlizumab for the prevention of pain crises in sickle cell disease. N Engl J Med. 2017:376(5):429-439.

82. Kalra VK, Zhang S, Malik P, et al. Placenta growth factor mediated gene regulation in sickle cell disease. Blood Rev. 2018;32(1):6170

83. Belcher JD, Marker PH, Weber JP, et al Activated monocytes in sickle cell disease: potential role in the activation of vascular endothelium and vaso-occlusion. Blood. 2000;96(7):2451-2459.

84. Mackman N. Regulation of the tissue factor gene. Thromb Haemost. 1997;78(1):747-754

85. Liu Y, Zhong $\mathrm{H}$, Bao W, et al. Patrolling monocytes scavenge endothelial-adherent sickle RBCs: a novel mechanism of inhibition of vaso-occlusion in SCD. Blood. 2019;134(7):579-590.

86. Furie B, Furie BC. Mechanisms of thrombus formation. N Engl J Med. 2008;359(9):938949.

87. Grover SP, Mackman N. Tissue factor: an essential mediator of hemostasis and trigger of thrombosis. Arterioscler Thromb Vasc Biol. 2018;38(4):709-725.

88. Witkowski M, Landmesser U, Rauch U. Tissue factor as a link between inflammation and coagulation. Trends Cardiovasc Med. 2016;26(4):297-303.

89. Giesen PL, Rauch U, Bohrmann B, et al Blood-borne tissue factor: another view of thrombosis. Proc Natl Acad Sci U S A. 1999;96(5):2311-2315

90. Solovey A, Somani A, Belcher JD, et al. A monocyte-TNF-endothelial activation axis in sickle transgenic mice: therapeutic benefit from TNF blockade. Am J Hematol. 2017;92(11):1119-1130.

91. Esmon CT. Role of coagulation inhibitors in inflammation. Thromb Haemost. 2001;86 (1):51-56.

92. Ansari SA, Pendurthi UR, Rao LVM. Role of cell surface lipids and thiol-disulphide exchange pathways in regulating the encryption and decryption of tissue factor. Thromb Haemost. 2019;119(6):860-870

93. Arumugam PI, Mullins ES, Shanmukhappa SK, et al. Genetic diminution of circulating prothrombin ameliorates multiorgan pathologies in sickle cell disease mice. Blood. 2015;126(15):1844-1855

94. Nasimuzzaman M, Malik P. Role of the coagulation system in the pathogenesis of sickle cell disease. Blood Adv. 2019;3(20): 3170-3180.

95. Leslie J, Langler D, Serjeant GR, et al. Coagulation changes during the steady state in homozygous sickle-cell disease in Jamaica. Br J Haematol. 1975;30(2):159-166.

96. Francis RB. Platelets, coagulation, and fibrinolysis in sickle cell disease: their possible role in vascular occlusion. Blood Coagul Fibrinolysis. 1991;2(2):341-353.

97. Hagger D, Wolff S, Owen J, et al. Changes in coagulation and fibrinolysis in patients with sickle cell disease compared with healthy black controls. Blood Coagul Fibrinolysis. 1995;6(2):93-99.

98. Noubouossie DF, Lê PQ, Corazza F, et al Thrombin generation reveals high procoagulant potential in the plasma of sickle cell disease children. Am J Hematol. 2012;87 (2):145-149.

99. Noubouossie DF, Henderson MW, Mooberry M, et al. Red blood cell microvesicles activate the contact system, leading to factor IX activation via 2 independent pathways. Blood. 2020;135(10):755-765

100. Whelihan MF, Lim MY, Mooberry MJ, et al Thrombin generation and cell-dependent hypercoagulability in sickle cell disease. Thromb Haemost. 2016;14(10):1941-1952.

101. Amin C, Adam S, Mooberry MJ, et al Coagulation activation in sickle cell trait: an exploratory study. Br J Haematol. 2015;171 
Prothrombotic state in sickle cell disease

(4):638-646

102. Stark K, Philippi V, Stockhausen S, et al. Disulfide HMGB1 derived from platelets coordinates venous thrombosis in mice. Blood. 2016;128(20):2435-2449.

103. Xu H, Wandersee NJ, Gu Y, et al. Sickle cell disease increases high mobility group box 1 : a novel mechanism of inflammation. Blood. 2014;124(26):3978-3981.

104. Merle NS, Grunenwald A, Rajaratnam H, et al. Intravascular hemolysis activates complemont via cell-free heme and heme-loaded microvesicles. JCI Insight. 2018;3(12): e96910.

105. Camus SM, De Morass JA, Benin P, et al. Circulating cell membrane microparticles transfer heme to endothelial cells and trigger vasoocclusions in sickle cell disease. Blood. 2015;125(24):3805-3814.

106. Reiter CD, Wang X, Tanus-Santos JE, et al. Cell-free hemoglobin limits nitric oxide bioavailability in sickle-cell disease. Nat Med. 2002;8(12):1383-1389.

107. Setty BN, Betal SG, Zhang J, et al. Heme induces endothelial tissue factor expression: potential role in hemostatic activation in patients with hemolytic anemia. J Thromb Haemost. 2008;6(12):2202-2209.

108. Merle NS, Pule R, Leon J, et al. P-selectin drives complement attack on endothelium during intravascular hemolysis in TLR4/heme-dependent manner. Proc Natl Acad Sci U S A. 2019;116(13):6280-6285.

109. Roumenina LT, Chadebech P, Bodivit G, et al. Complement activation in sickle cell disease: dependence on cell density, hemolysis and modulation by hydroxyurea therapy Am J Hematol. 2020;95(5):456-464.

110. Sparkenbaugh EM, Chen C, Brzoska T, et al. Thrombin-mediated activation of PAR-1 contributes to microvascular stasis in mouse models of sickle cell disease. Blood. 2020;135(20):1783-1787.

111. Gilbert GE, Sims PJ, Wiedmer T, et al. Platelet-derived microparticles express high affinity receptors for factor VIII. J Biol Chem. 1991;266(26):17261-17268.

112. Hrachovinova I, Cambien B, HafeziMoghadam A, et al. Interaction of P-selectin and PSGL-1 generates microparticles that correct hemostasis in a mouse model of hemophilia A. Nat Med. 2003;9(8):10201025.

113. Gross PL, Furie BC, Merrill-Skoloff G, et al. Leukocyte-versus microparticle-mediated tissue factor transfer during arteriolar throwbus development. J Leukoc Biol. 2005;78(6):1318-1326.

114. Eaton WA, Bun HF. Treating sickle cell disease by targeting $\mathrm{HbS}$ polymerization. Blood. 2017;129(20):2719-2726.

115. Ranque B, Menes A, Boutouyrie P, et al. Arterial stiffness impairment in sickle cell disease associated with chronic vascular complications: the multinational African CADRE study. Circulation. 2016;134(13) :923-933.

116. Belhassen L, Pule G, Sediame S, et al. Endothelial dysfunction in patients with sickle cell disease is related to selective impairment of shear stress-mediated vasodilation. Blood. 2001;97(6):1584-1589.

117. Powars DR, Chan LS, Hit A, et al. Outcome of sickle cell anemia: a 4-decade observatonal study of 1056 patients. Medicine (Baltimore). 2005;84(6):363-376.

118. Mehari A, Gladwin MT, Than X, et al. Mortality in adults with sickle cell disease and pulmonary hypertension. JAMA. 2012;307(12):1254-1256

119. Kearon C, Ak EA, Ornelas J, et al. Antithrombotic therapy for VTE disease: CHEST guideline and expert panel report. Chest. 2016;149(2):315-352.

120. Tritschler T, Kraaijpoel N, Le Gal G, et al. Venous thromboembolism: advances in diagnosis and treatment. JAMA. 2018;320 (15):1583-1594.

121. Diem RI, Lanzkron S, Coates TD, et al. American Society of Hematology 2019 guidelines for sickle cell disease: cardiopulmonary and kidney disease. Blood Adv. 2019;3(23):3867-3897.

122. Hariharan N, Bronson A, Mahajan A, et al. Bleeding in patients with sickle cell disease: a population-based study. Blood Adv. 2020;4(5):793-802.

123. van Es N, Coppers M, Schuman S, et al. Direct oral anticoagulants compared with vitamin $\mathrm{K}$ antagonists for acute venous thromboembolism: evidence from phase 3 trials. Blood. 2014;124(12):1968-1975.

124. Li A, Garcia DA, Lyman GH, et al. Direct oral anticoagulant (DOAC) versus low-molecular-weight heparin (LMWH) for treatmont of cancer associated thrombosis (CAT): a systematic review and meta-analysis. Thromb Res. 2019;173:158-163.

125. Roberts MZ, Gaskill GE, Kanter-Washko J, et al. Effectiveness and safety of oral antico- agulants in patients with sickle cell disease and venous thromboembolism: a retrospective cohort study. J Thromb Thrombolysis. 2018;45(4):512-515.

126. Patel A, Williams $H$, Boer MR, et al. Decreased bleeding incidence with direct oral anticoagulants compared to vitamin $\mathrm{K}$ antagonist and low-molecular-weight heparin in patients with sickle cell disease and venous thromboembolism. Act Haematol. 2019:142(4):233-238.

127. Colella MP, De Paula EV, Conman N, et al. Hydroxyurea is associated with reductions in hypercoagulability markers in sickle cell anemia. J Thromb Haemost. 2012;10(9): 1967-1970.

128. Falange A, Marchetti M. Thrombosis in myeloproliferative neoplasms. Serin Thromb Hemost. 2014;40(3):348-358.

129. Kutlar A, Ranter J, Lilies DK, et al. Effect of crizanlizumab on pain crises in subgroups of patients with sickle cell disease: a SUSTAIN study analysis. Am J Hematol. 2019;94(1): 55-61.

130. Heeney MM, Hope CC, Abboud MR, et al. A multinational trial of prasugrel for sickle cell vaso-occlusive events. $N$ Engl J Med. 2016;374(7):625-635.

131. Weitz JI, Chan NC. Novel antithrombotic strategies for treatment of venous throwboembolism. Blood. 2020;135(5):351-359.

132. Duller HR, Bethune C, Bhanot S, et al. Factor $\mathrm{XI}$ antisense oligonucleotide for prevention of venous thrombosis. N Angl J Med. 2015;372(3):232-240.

133. Brighton TA, Eikelboom JW, Mann K, et al. Low-dose aspirin for preventing recurrent venous thromboembolism. $\mathrm{N}$ Eng J Med. 2012;367(21):1979-1987.

134. Glynn RJ, Danielson E, Fonseca FA, et al. A randomized trial of rosuvastatin in the orevention of venous thromboembolism. N Encl J Med. 2009;360(18):1851-1861.

135. Hope C, Jacob E, Styles L, et al. Simvastatin reduces vaso-occlusive pain in sickle cell anaemia: a pilot efficacy trial. Br J Haematol. 2017;177(4):620-629.

136. Ridker PM, Everett BM, Thuren T, et al. Antiinflammatory therapy with canakinum$\mathrm{ab}$ for atherosclerotic disease. N Angl J Med. 2017;377(12):1119-1131.

137. Austin H, Key NS, Benson JM, et al. Sickle cell trait and the risk of venous thromboembolism among blacks. Blood. 2007;110(3): 908-912.

haematological | 2020; 105(10)

2379 